\title{
La implementación del Convenio 169 de la OIT en Chile: La paradoja de los derechos indígenas
}

\author{
The implementation of ILO Convention 169 in Chile: \\ The paradox of Indigenous rights
}

Fernando Quilaleo Aguirre

Universidad Nacional de Cuyo, Argentina

\begin{abstract}
RESUMEN El modelo de vida occidental construyó una racionalidad, llamada modernidad, que permitió la inclusión dentro de sus parámetros reflexivos a toda otredad existente más allá de sus fronteras civilizatorias. En el siglo XX se creó el sistema internacional de los derechos humanos y también el sistema de derechos de los pueblos indígenas. Una manifestación concreta en Chile de este sistema fue la ratificación del Convenio 169 de la Organización Internacional del Trabajo. En los últimos años este tratado ha presentado dificultades de legitimación, porque los actores no expresan una evaluación positiva de su proceso de implementación. Una explicación posible es que el Convenio 169 tensiona y enfrenta a dos modelos de vida, el de la globalización y el de los pueblos indígenas. Los pueblos indígenas con sus reclamaciones llevan al límite de sus posibilidades esta arquitectura racional de la modernidad. Los problemas del Convenio 169 no serían solo problemas de aplicabilidad, sino que al hacer planteamientos para la defensa de las formas de vida de los pueblos indígenas, lleva a una crisis general a toda la arquitectura jurídico-filosófica que sustenta al Estado y su modernidad.
\end{abstract}

PALABRAS CLAVE Convenio 169, derechos indígenas, modernidad, modelos de vida indígenas, voluntad plurinacional.

ABSTRACT The Western life model built a rationality, called Modernity, which allowed the inclusion within its reflective parameters of all the others existing beyond its civilizing borders. In the 2oth century, the International System of Human Rights was created, as well as the System of Rights of Indigenous Peoples. A concrete manifestation in Chile of this system was the ratification of Convention 169 of the International Labour Organization. In recent years this treaty has presented legitimacy difficulties, because the actors do not express a positive evaluation of its implementation process. One possible explanation is that Convention 169 stresses and confronts two models of life: globalization and the way of life of indigenous peoples. The indigenous peoples with their claims 
take this rational architecture of Modernity to the limits of its possibilities. The problems of Convention 169 would not only be problems of applicability, but in making proposals for the defense of the indigenous peoples' ways of life, it leads to a general crisis of the whole legal-philosophical architecture that sustains the State and its modernity.

KEYWORDS Convention 169, indigenous rights, Modernity, indigenous life models, plurinational will.

\section{Presentación}

¿Qué es una paradoja? Aceptemos como uso corriente que paradoja es un argumento que se contradice a sí mismo. En general, el lenguaje presenta varias paradojas que han sido analizadas por diversas disciplinas, entre otras, la filosofía, la lógica y las matemáticas. «Alguien afirma que está mintiendo. ¿Dice la verdad o miente?». Es un mentiroso, no hay que creer en lo que dice; entonces, si es mentiroso y no dice la verdad, el resultado sería que «no es mentiroso», por tanto, dice la verdad; ergo, «es mentiroso». A este juego de palabras suele conocérsele como «paradojas del lenguaje»."

Lo que se intenta mostrar a continuación como una paradoja y una contradicción epistemológica es la defensa que hacen los pueblos indígenas de un modelo de vida ${ }^{2}$ propio en el marco del sistema internacional de los derechos humanos que pertenece a un modelo de vida, o civilizatorio, distinto. Lo que se busca mostrar son los límites de esa defensa de las condiciones particulares de vida de un grupo humano con un trayecto de vida sociocultural y sociopolítico en el marco de referencia de otro grupo humano, en ciertos aspectos, de oposición y dominación. Se considera la existencia de una contradicción basal, ya que se defiende la existencia de los pueblos indígenas, ${ }^{3}$ sus prácticas culturales, sus formas de pensamientos y creencias, la soberanía sobre sus recursos simbólicos y materiales, en un ámbito y marco lógico de un modelo de vida ajeno o un modelo civilizatorio ajeno.

\footnotetext{
1. Se dice que el filósofo griego Epiménides de Cnosos (ciudad en Creta) argumentó que «todos los cretenses son mentirosos» en el siglo VI antes de Cristo. Otro filósofo griego, Eubulides de Mileto, habría dicho también que «un hombre afirma que está mintiendo. Lo que dice es verdadero o falso» en el siglo IV antes de Cristo. Las paradojas del lenguaje suelen dividirse en paradojas semánticas o retóricas y paradojas de metalenguajes.

2. Más detalles sobre las dos visiones de vida y sus propuestas de nuevas sociedades interculturales y estados plurinacionales, en el texto institucional de FILAC (2010).

3. El término «pueblos indígenas» se entenderá, para el presente artículo, como una categoría jurídica del derecho internacional. A su vez, la categoría de «pueblos originarios» es considerada una definición de uso político que aún no alcanza a permear al derecho positivo de derechos de los pueblos indígenas a nivel internacional. Para fines prácticos, «pueblos indígenas» y «pueblos originarios» se entenderán como sinónimos.
} 
El modelo de vida llamado occidental construyó para sí una racionalidad que permitió la inclusión dentro de sus parámetros reflexivos a toda otredad existente más allá de sus fronteras civilizatorias. En años recientes, este modelo se ha conocido como globalización, que es la expansión y expresión universal de aquella racionalidad moderna. El pensamiento ilustrado extendió por el planeta una forma de entender al ser humano y una visión de mundo que ubica en el centro de sus creencias la pretensión teórica de que cada uno de los actos expresados por el ser humano puede ser condicionado por el uso de su razón.

Esto, que pareciera ser un debate distante, se manifiesta en hechos bastante concretos relacionados con los derechos humanos y, muy en particular, con los derechos humanos de los pueblos indígenas en Chile. Una manifestación de estos límites epistemológicos sería la orfandad en que ha caído el Convenio 169 de la Organización Internacional del Trabajo (OIT) sobre pueblos indígenas a pocos años de su promulgación. ${ }^{4}$

\section{Los derechos indígenas en la modernidad globalizada}

Si bien nadie podría negar los avances que ha significado para la humanidad el enfoque de derechos humanos a nivel planetario, un resumen de su implementación o adopción por las naciones deja ciertas dudas de su eficacia operativa o, al menos, de la voluntad de respeto de sus directrices. Hace diez años, Amnistía Internacional se quejaba de esta realidad e intitulaba su anuario como «1948-2008: 60 años de fracaso en derechos humanos», además de escribir: «La injusticia, la desigualdad y la impunidad son hoy las marcas distintivas de nuestro mundo. Los Gobiernos tienen que actuar ya para acabar con el abismo que separa lo que se dice de lo que se hace».5 Según la organización, la mayor amenaza para el futuro de los derechos humanos en el mundo era la ausencia de una visión compartida de sus obligaciones. Es probable que esta realidad no haya cambiado en la última década.

Occidente generó un sistema de resolución de disputas internacionales y protección de derechos para la humanidad. Debieron pasar muchos años y, por cierto, muchas guerras para construir esta arquitectura de resolución pacífica de conflictos, acompañado de la formación de un dispositivo de defensa del conjunto de principios y normas que sustentan ideas de justicia en la regulación de las relaciones humanas en todas las sociedades. Lo que se llama en las últimas décadas «globalización» no es

4. Otro ejemplo puede ser la extensa huelga de hambre del machi Celestino Córdova solicitando un permiso de 48 horas para asistir a su comunidad a reemplazar su rewe, que lo nutre de vida espiritual, y la resistencia de las autoridades. Al término de este artículo, la huelga de hambre finalizó, pero no el conflicto que la generó.

5. «6o años de fracaso en derechos humanos: Los Gobiernos tienen que disculparse y actuar ya», Amnistía Internacional, 28 de mayo de 2008, disponible en http://bit.ly/2CCkMBC. 
más que la expansión máxima de la modernidad, que consiguió que sus creencias se impusieran a otras visiones de mundo. ${ }^{6}$ Esta pretensión teórica, y por cierto racional, logró imponer una visión de mundo o cosmovisión, la razón occidental, o como la hemos denominado en la discusión mapuche, la «razón wigka». Esta razón wigka se extendió por el planeta en los últimos siete siglos con exploraciones y conquistas (Zavala, 1994; Zea, 1981) que llevaron a Europa a ampliar sus fronteras. Así, fueron promotores de esta cosmovisión Cristóbal Colón, Hernando de Magallanes y Sebastián Elcano en el comercio; Darwin y Humboldt en las ciencias; Las Casas y Ginés de Sepúlveda en la religión, entre muchos otros viajeros de la luz ilustrada.

Habría que esperar hasta el siglo XX, con su enorme revolución de las comunicaciones, para asistir a la occidentalización definitiva de la conciencia reflexiva planetaria. El argumento que Europa y su modernidad pusieron sobre la mesa de discusión para doblegar a otras formas y modelos de vida, sobre todo otras culturas y filosofías, fue la primacía de la ciencia y la eficacia de su tecnología por encima de cualquier otra forma de conocimiento (Pérez, 1998). Una ciencia capaz de comprender la física estelar y los misterios de la microbiología, una racionalidad versátil que se impone a la naturaleza, la explica y la controla.

La racionalidad moderna se instala vencedora, no solo por las armas, sino por el triunfo de una forma de pensamiento incubado entre los siglos XIII al XV en un extenso proceso conocido como Renacimiento, Iluminismo o Ilustración, potenciado por la acumulación de riquezas materiales y simbólicas que significó la conquista del «Nuevo Mundo» a partir de 1492 con una expedición que impulsaría el desencuentro entre Europa y los pueblos originarios de América:

El fenómeno que lanzó a Europa a autointerpretarse de manera completamente nueva fue, exactamente, la expansión que se produjo en 1492, cuando un Nuevo Mundo vino a cambiar cotidiana y geopolíticamente la vida y el pensamiento de todos los europeos $-\mathrm{y}$, por supuesto, la vida y el pensamiento de todos los pueblos «impactados» en la «periferia» por tal evento [...] Hasta el 1492, las historias de todas las culturas habían sido, inevitablemente, regionales (Dussel, 1990: 88).

La Conquista fue una empresa multifacética que consiguió - gracias al desarrollo de las tecnologías de guerra, la pólvora como armamento-imponerse en los territorios ancestrales de los pueblos del Nuevo Mundo e inauguró un extenso periodo de etnocidio e invasión. Esa misma contradicción entre destrucción y nueva conciencia universal llevaría a disputas y controversias filosóficas profundas, como las que

6. Zigmunt Bauman señalaba que «la globalización, según parece, tiene más éxito para reavivar la hostilidad intercomunitaria que para promover la coexistencia pacífica de las comunidades» (citado en Díaz-Polanco, 2006: 136). 
enfrentaron a Bartolomé de las Casas y Ginés de Sepúlveda.7 Para algunos, en esta disputa por el alma de los indios y la validez de la justa guerra de Conquista se encontrarían los orígenes concretos de la actual noción de derechos humanos y el posterior sistema internacional de protección a esos derechos (Anaya, 2005).

Es probable que sin los tesoros de la Conquista arrebatados en toda Abya Yala o en los territorios de Anáhuac, del Tawantinsuyu o en el Wallmapuche, la Europa moderna no hubiera sido posible, como tampoco habrían existido las revoluciones industriales que la prosiguieron, ni tampoco la arquitectura del sistema internacional de resolución de conflictos entre naciones. Para que existiera el Primer Mundo, se necesitó que existiera a la par un Tercer Mundo, y hasta un Cuarto, aquél de los excluidos dentro de los Estados nacionales periféricos.

La racionalidad moderna fue creando e imponiendo su actitud de vida, transformando y destruyendo otras concepciones del espacio y del tiempo. Cada concepto debió tener valor racional para ser o no ser, para ser considerada verdad o no. La conquista no fue solo de los territorios y las cosas, sino también sobre los cuerpos y los espíritus. Una nueva validación del ser, ahora transmutada en «tener», en el que los valores, el saber, la existencia, el trascender, se subordinaron al tener, y el tener al poder. Tener como poder, como una téchne de relaciones de poder y de imposición de una verdad. ${ }^{8}$

La tendencia general de los sistemas de derechos occidentales es que están orientados a la universalidad, y esto ha devenido en un régimen internacional de derechos humanos que busca, entre varios objetivos, que los Estados miembros garanticen a los pueblos indígenas que viven al interior de sus fronteras un conjunto de reconocimientos explícitos a sus prácticas culturales, ya no solo de sus derechos individuales incluidos en Declaración Universal de 1948 y en los Pactos de 1966 -el de Derechos Civiles y Políticos y el de Derechos Económicos, Sociales y Culturales-, sino también avanzar hacia el reconocimiento de derechos colectivos, conocidos como derechos de tercera o cuarta generación.

Desde hace un par de décadas, se asentó la existencia de un sistema internacional de los derechos de los pueblos indígenas que corresponde, principalmente, a un conjunto de instituciones ligadas a la Organización de Naciones Unidas que incluye, entre otros, al Convenio 169 de la OIT; la Declaración de Naciones Unidas sobre los

7. Una forma entretenida de adentrarse en esta disputa intelectual, religiosa y filosófica es la producción «La controversia de Valladolid» de Jean-Daniel Verhaeghe de 1991, disponible en https://youtu. be/1SukXDBBx8A.

8. Una interesante conceptualización es la desarrollada por Michel Foucault al definir estas redes de relaciones y control de la verdad, o de cómo una verdad se impone a otras verdades posibles, que él denominó «tecnologías de poder»: «El caso de la penalidad me convenció de que el análisis no debía hacerse en términos de derecho precisamente, sino en términos de tecnología, en términos de táctica y estrategia» (Foucault, 1992: 154). 
Derechos de los Pueblos Indígenas de 2008; el Foro Permanente para Cuestiones Indígenas; dos declaraciones del Decenio Internacional de las Poblaciones Indígenas del Mundo (1995-2004 y 2005-2014); la Comisión y la Corte Interamericana de Derechos Humanos, donde se han visto casos emblemáticos, y los nombramientos de relator especial sobre los derechos de los pueblos indígenas, Rodolfo Stavenhagen, James Anaya y, en la actualidad, Victoria Tauli-Corpuz, todos dependientes del Alto Comisionado para los Derechos Humanos; la Declaración Americana sobre Derechos de los Pueblos Indígenas de 2016, y otros mecanismos regionales. Este sistema americano forma parte de lo que se conoce como sistema internacional de los derechos humanos.

\section{La situación en Chile}

Con cierto grado de retraso, las políticas estatales chilenas siguieron después de la segunda mitad del siglo XX a la discusión internacional sobre los derechos de los pueblos indígenas y la grave situación de marginalidad y exclusión en que vivían. La historia de Chile, como la de América Latina, orientó sus esfuerzos desde el origen de la república a la asimilación de los pueblos indígenas. Chile vio generarse y morir variadas propuestas políticas hacia los pueblos, desde las asimilacionistas y destructivas, hasta las integradoras, desarrollistas y, en las últimas décadas, un modelo de reconocimiento de derechos. ${ }^{9}$

A su turno, los movimientos indígenas levantaron su voz $-\mathrm{y}$ su físico- para exigir, primero, su derecho a vivir, su facultad de seguir manifestando sus valores, prácticas culturales y condiciones de vida. Segundo, levantaron exigencias de reconocimiento de sus derechos, de reconocimientos constitucionales en los Estados y repúblicas donde habitan y la invocación de un sistema normativo internacional que los ampare y respalde en sus demandas, por medio de una intensa diplomacia indígena. ${ }^{10}$

En casi toda América, los movimientos indígenas pasaron de levantar demandas a exigir derechos utilizando el marco jurídico internacional como «efecto rebote» sobre el desarrollo jurídico nacional y, en los últimos años, buscaron ganar para sí ciertos derechos consagrados y reservado en el sistema internacional a "pueblos li-

9. Fernando Quilaleo Aguirre, «Chile Bicentenario: De las comunidades inventadas a la comunidad diversa», Focal Point, 28 de octubre de 2006, disponible en http://bit.ly/2CFdxJ1.

10. Las luchas de los pueblos indígenas en permanente conflicto con los Estados y sus gobernantes se han extendido a este frente jurídico y lo ha trasformado en una plataforma política para proyectar sus causas y conseguir aliados y respaldos en el concierto internacional. Podemos afirmar que, en la práctica, casi no existe un intersticio en los foros o reuniones internacionales de Naciones Unidas en el que los derechos humanos de los pueblos indígenas no se encuentren, en algún punto, en debate y tensión. A este activismo en foros internacionales se le llama diplomacia indígena (Torres Cisneros, 2013). 
bres», como los derechos a la libre determinación, el autogobierno y la autonomía, además de otros derechos políticos y participatorios (FILAC, 2004). Estos planteamientos llevaron al límite las posibilidades de aceptación o concesión en el modelo de existencia de los derechos. Las exigencias de reconocimiento de derechos por los pueblos indígenas tensionaron la «voluntad multicultural», de la mano del debilitamiento de las esperanzas puestas sobre, por ejemplo, el Convenio 169 de la OIT, que fue quedando en duda rápidamente respecto de sus posibilidades de expresión de los derechos demandados o exigidos. Por el contrario, surgieron sus límites e imposibilidades. La explicación a estas limitaciones se buscó, principalmente, en sus formas de aplicación. ${ }^{11}$

\section{La orfandad del Convenio 169}

Chile ratificó el Convenio 169 de la OIT el 15 de septiembre de 2007 y entró en vigor doce meses después, para lo cual los pueblos indígenas debieron esperar casi veinte años. ${ }^{12}$

Esta ratificación abrió todo tipo de expectativas. Para los pueblos indígenas, el Convenio 169 era el único instrumento internacional vinculante sobre derechos indígenas internacional de sistema de derechos humanos que obligaba a adecuar sus normas internas a los Estados signatarios (Zalaquett Daher, 2008: 144). Para el Estado de Chile y los promotores de políticas públicas, era una conquista que permitiría mejorar las relaciones con los pueblos indígenas, deterioradas desde fines de la década de los noventa por, entre otras razones, el impulso a las centrales hidroeléctricas Pangue y Ralco en el río Biobío, como por el debilitamiento institucional de la Corporación Nacional de Desarrollo Indígena (Conadi), un proceso creciente de «deslegitimación de la institucionalidad indígena. La Conadi deja así de ser un or-

11. Entre los puntos críticos de la aplicación se argumentaba que había deficiencias o faltas de «inclusividad, transparencia, equidad e igualdad, participación, empoderamiento, procesos de deliberación, adecuación a los temas, los pueblos y los territorios, ejecución de buena fe de los acuerdos», entre los principales. Salvador Millaleo y Ariel León, «Consulta indígena: Entre el fracaso y la necesaria legitimidad», El Quinto Poder, 24 de julio de 2013, disponible en http://bit.ly/2C9Ujdq.

12. En algunos foros se suele escuchar que la ratificación del Convenio 169 de la OIT fue parte del Acuerdo de Nueva Imperial. Lo cierto es que el Convenio no fue parte de la discusión ni quedó registrado en el documento del 1 de diciembre de 1989. Ese acuerdo consideraba dos compromisos de los pueblos signatarios, que suelen pasarse por alto, y tres compromisos del futuro Gobierno democrático. Las organizaciones firmantes se comprometían a: i) apoyar y defender al futuro Gobierno de la Concertación, y ii) «canalizar sus legítimas demandas a aspiración de justicia frente a los graves problemas que afectan a los pueblos indígenas a través de las instancias y mecanismos de participación que serán creados por el futuro Gobierno». Esto último apuntaba a terminar con los procesos de recuperaciones de tierras, cuestión que llevó a algunos dirigentes a marginarse y no concurrir con su firma. El documento se encuentra en el Centro de Políticas Públicas y Derechos Indígenas, disponible en http://bit.ly/2CajPzn. 
ganismo representativo de demandas fundamentales para los pueblos indígenas» (Figueroa Huencho, 2016: 467).

Las relaciones también se deterioraron en forma progresiva por la aplicación de leyes especiales en contra de organizaciones y líderes mapuche. Entre ellas, destacan al inicio de la transición democrática la invocación de la Ley de Seguridad Interior del Estado en contra de 144 dirigentes del Consejo de Todas las Tierras y sus líderes ${ }^{13}$ y la ley antiterrorista (Ley 18.314). Esto llevó a una creciente y generalizada desconfianza de los distintos actores indígenas. ${ }^{14}$ Habría que añadir las acciones violentas y la fuerte represión policial, que terminó por cobrar varias vidas de jóvenes dirigentes mapuche y llevó a la irrupción de la Coordinadora Arauco-Malleco. ${ }^{15}$

En ese contexto, la ratificación del Convenio 169, luego de diez años de conflicto entre el Estado de Chile y el pueblo mapuche, generó la esperanza en distintos líderes indígenas y no indígenas de que aquel instrumento de derecho internacional podría convertirse en un puente de entendimiento para las deterioradas relaciones interétnicas (Sanhueza y otros, 2013).

La implementación del Convenio 169 ha sido un desafío para todos los involucrados. Las expectativas han fallado en los resultados alcanzados, se elevan las críticas y los participantes de los procesos de consulta previa caen en desazón y desesperanza. Tras pocos años, el Convenio 169 comenzó a mostrar sus limitaciones, especialmente en las restricciones de los únicos derechos de aplicación inmediata contenidos en él: el derecho a consulta previa y el derecho a participación (artículos 6 y 7). Los aspectos axiológicos y de derechos humanos invocados en el Convenio 169 fueron más o menos aceptados por todos los sectores, pero su metodología de aplicación y sobre todo los resultados esperados por los actores fueron rápidamente desperfilando su potencia.

Se debe considerar que un proceso modelo de consulta previa $-o$ consulta indígena, como se suele llamar en Chile- debe gozar de consistencia y legitimidad. ${ }^{16}$

13. Una de las primeras organizaciones a las que se les aplicó legislación de Seguridad Interior en democracia fue, precisamente, a una mapuche del Aukiñ Wallmapu Gvlam (Consejo de Todas las Tierras).

14. Tanto la aplicación de la ley antiterrorista como la Reforma Procesal Penal, la persecución policial, los allanamientos, la existencia de presión política en contra de dirigentes y, por cierto, el asesinato de varios jóvenes dirigentes mapuche, han deteriorado las relaciones del pueblo mapuche con el Estado de Chile y las han llevado a convertirse en, quizás, el principal problema político en el país.

15. «Se dice que todos menos uno de los sentenciados o acusados de terrorismo pertenecen o han pertenecido a la Coordinadora de Comunidades en Conflicto Arauco-Malleco (CAM), organización mapuche cuyos orígenes se remontan a una reunión de febrero de 1998 organizada por la Coordinadora Territorial Lafkenche, a la que asistieron muchas organizaciones mapuche». Human Rights Watch, «Indebido proceso: Los juicios antiterroristas, los tribunales militares y los mapuche en el sur de Chile», informe, octubre de 2004, disponible en http://bit.ly/2C9WayU.

16. Más detalles sobre críticas al estándar metodológico de la consulta indígena en Fernando Quilaleo 
Consistencia, por un lado, en su estructura procedimental o su estructura interna: las consideraciones internas de un proceso de consulta indígena hacen referencia a sus principios fundantes, a su metodología de aplicación y a un modelo procedimental consistente. Por otro lado, legitimidad es la validez que se otorga a la consulta por su expresión externa o contextual.

Una de las manifestaciones más claras de esta validez externa está dada por los resultados obtenidos. Existe una brecha cada vez más amplia entre los resultados esperados por los Estados y los pueblos interesados, y los alcanzados por los procesos de consulta. Esta brecha, que podríamos llamar de "resultados» o de "finalización», pareciera ser el centro de las principales críticas de los actores indígenas. ${ }^{17}$ Por una parte, hay cierto grado de consenso sobre la validez de los fundamentos filosóficojurídicos que sustentan al Convenio 169 y los derechos que resguarda; por otra parte, no existe un estándar metodológico o procedimental para su implementación, ni siquiera lo disponen los mismos organismos o expertos internacionales que lo promueven. ${ }^{18}$ Se debe sumar que la experiencia de los pueblos indígenas y sus líderes en estos procesos de relación con el Estado en Chile es mucho menor, y quizás sea una razón más para que se tensionen. En el periodo entre 2008 y 2017, la cantidad de consultas indígenas fue de 122, como muestra la tabla 1.

La metodología de aplicación fue duramente cuestionada por los dirigentes indígenas. Su lógica procedimental quedó contenida en sendos documentos: el Reglamento General de Aplicación 66 (Ministerio de Desarrollo Social) y el Reglamento 40 del Sistema de Evaluación de Impacto Ambiental (Ministerio de Medio Ambiente). Ambos comenzaron a mostrar dificultades de implementación y generaron, a gran velocidad, el desencanto de las comunidades afectadas y la judicialización de sus procedimientos.

Las expectativas de cada sector eran muy disímiles. Para los pueblos indígenas, el Convenio 169 debía ser un «dique de contención» que frenase, entre otros, los distintos megaproyectos que buscaban instalarse en territorios indígenas. Para el Estado, era una suerte de «piedra en el zapato» que había servido para mejorar las deteriora-

\footnotetext{
Aguirre, «Procesos de consulta indígena: Consistencia y legitimidad», Análisis Informativo, 8 de febrero de 2015, disponible en http://bit.ly/2CcxbLJ.

17. Sobre estos aspectos puede consultarse el trabajo de Millaleo (2014: 97-98), en el cual el académico concluye, entre otras ideas, que «el fundamento moral y político de la consulta indígena es la justicia puramente procedimental» y que «todos los reglamentos fueron formados en procesos inexistentes o profundamente defectuosos de consulta a los pueblos indígenas en Chile. La ausencia o desviación sobre tales mecanismos de consulta ha convertido todo el proceso posterior ilegítimo para los actores indígenas».

18. Véase, por ejemplo, el Manual para los mandantes tripartitos de la OIT, perteneciente al Programa PRO 169, que intenta dar claridad de la formulación, pero que no alcanza a precisar una metodología apropiada. Documento disponible en http://bit.ly/2Ccrltx.
} 
Tabla 1. Procesos de consultas indígenas en Chile entre 2008 y 2017

\begin{tabular}{|lcc|}
\hline Servicio público & Consultas finalizadas & Consultas en proceso \\
\hline Ministerio de Obras Públicas & 27 & 24 \\
\hline Servicio de Evaluación Ambiental & 27 & 16 \\
Ministerio de Bienes Nacionales & 6 & 0 \\
Ministerio de Desarrollo Social & 5 & 0 \\
Ministerio de Energía & 3 & 2 \\
Ministerio de Educación & 3 & 0 \\
Ministerio de Medio Ambiente & 2 & 0 \\
Ministerio de Agricultura y Conaf & 2 & 0 \\
Ministerio del Interior y Seguridad Pública & 1 & 1 \\
Ministerio de las Culturas, las Artes y el Patrimonio & 1 & 0 \\
Ministerio de Salud & 1 & 0 \\
Consejo de Monumentos Nacionales & 1 & 0 \\
\hline Totales & 79 & 43 \\
\hline
\end{tabular}

Fuente: Elaboración propia a partir de información de la Unidad de Consulta Indígena del Ministerio de Desarrollo Social.

das relaciones, pero que implicaba serias dificultades de implementación. Por último, los empresarios y desarrolladores de proyectos consideraban al Convenio 169 como un "palo en la rueda» para sus inversiones, ya que las retrasaban y las encarecían. El Convenio 169 quedó abandonado a su suerte y pocas son las voces que lo defienden: lo más escuchado en debates, seminarios y conversatorios son críticas.

Que el Convenio 169 muestre una orfandad inquietante hace pensar que no tiene solo que ver con el modelo procedimental de su aplicación, que lleva al desencanto de los líderes y organizaciones indígenas. Quizás lo que hay detrás es que, alcanzado cierto nivel de confianza o construcción del propio modelo de vida de los pueblos indígenas, toda la arquitectura jurídica comienza a quedar corta ante la distancia que se manifiesta entre las esperanzas de los pueblos indígenas de seguir viviendo como lo han hecho, y la autoridad de los Estados y sus dispositivos jurídicos internos, que no están dispuestos a aceptar ningún fraccionamiento o dilución de los dogmas sobre los cuales se construyó el Estado, como son la nación única e indivisible, la división de poderes, la democracia liberal, el sistema penal, la titularidad sobre los recursos naturales y, lo que es más asombroso, la lógica persistente del poder soberano en manos de las élites familiares, lo que se llamó por años oligarquía: la titularidad de los destinos de los Estados sobre los hombros de un puñado de familias fundadoras que 
reclaman para sí la soberanía absoluta de los destinos de los Estados nacionales y sus sociedades (Salazar, 2015). ${ }^{19}$

\section{Conclusiones}

Una explicación posible de la situación de orfandad actual del Convenio 169 en Chile tiene que ver con que los derechos que defienden los pueblos indígenas ponen en tensión la arquitectura basal del sistema de derechos generado por el modelo de vida occidental. Esta arquitectura está amparada en la racionalidad moderna, sobre la cual se levanta todo el layout de la modernidad, en el que emergieron los derechos humanos y, a posteriori, los derechos de pueblos indígenas.

Chile asiste, quizás, a una crisis o punto de catástrofe del modelo occidental de relaciones amparadas en una lógica de los derechos; los pueblos indígenas con sus reclamaciones llevan al límite de sus posibilidades esta arquitectura racional. El problema pareciera ser ya no el consenso sobre los derechos otorgados a los pueblos indígenas, ni la capacidad del Estado para responder a ellos. No sería entonces un problema de aplicación del Convenio, ni de la buena fe, ni siquiera metodológico o de los recursos dispuestos para su aplicabilidad. El Convenio 169 se situaría en el borde de la racionalidad moderna, cualquier avance o exigencia de los pueblos más allá de este límite hace tambalear la tarima sobre la cual reposa el arreglo - o contrato- que permite la existencia del Convenio $169 \mathrm{y}$, en general, quizás de todo el modelo de derechos occidental globalizado. Éste sería un punto de catástrofe para la racionalidad moderna que sustenta el sistema.

Los propios pueblos no pueden hacer otra cosa que seguir defendiendo su modelo de vida, y es altamente improbable que el Estado y el sistema internacional de los derechos humanos disponga de un arreglo o salida distinta, que no tensione o, cuando no, socave las bases mismas sobre las cuales se levanta todo el edificio jurídico-político del sistema de derechos conocido y lo vuelva un sistema inestable.

En estas condiciones, la continuidad del Convenio 169 corre el riesgo del desamparo y el abandono no solo del Estado, sino de los propios pueblos indígenas que cobijaron en él las esperanzas de defensa de sus formas de vida. Cuando las voces indígenas no busquen fortalecer el Convenio, no busquen defenderlo, a pesar de sus debilidades y limitaciones; y no busquen usarlo, a pesar de sus problemas de aplicación, entonces el Convenio 169 puede correr el riesgo de desaparecer. Otra posibilidad es que los pueblos indígenas, amparados en la voluntad de un nuevo contrato social multicultural o, en los últimos años, un contrato plurinacional o, lo que es lo mismo,

19. «Para Salazar, la clase política chilena se habría constituido como un verdadero gremio, haciendo uso de un manifiesto lucro político que habría terminado por usurpar la soberanía popular» (Riveros, 2016: 279). 
desplegando una voluntad plurinacional, busquen otros y mejores instrumentos para proteger sus derechos.

\section{Referencias}

Anaya, James (2005). Los pueblos indígenas en el derecho internacional. Madrid: Trotta.

Díaz-Polanco, Héctor (2006). Elogio de la diversidad: Globalización, multiculturalismo y etnofagia. Ciudad de México: Siglo XXI.

Dussel, Enrique (1990). «1492: Diversas posiciones ideológicas». En Heinz Dieterich (coordinador), 1492-1992, La interminable conquista: Emancipación e identidad en América Latina. Ciudad de México: Joaquín Mortiz, Planeta.

Figueroa Huencho, Verónica (2016). «Pueblos indígenas y políticas públicas: El proceso de formulación de la política indígena en Chile en el Gobierno de Eduardo Frei Ruiz-Tagle, 1994-2000». Gestión y Políticas Públicas, 25 (2): 447-482. Disponible en http://bit.ly/2PupnIJ.

FILAC, Fondo para el Desarrollo de los Pueblos Indígenas de América Latina y el Caribe (2004). Foro Internacional sobre Participación de los Pueblos Indígenas Originarios y Formas de Representación. La Paz: Ministerio de Asuntos Indígenas y Pueblos Originarios.

-. (2010). Modelos de vida de los pueblos indígenas: Maya, quechua, aymara, guaraní, mapuche, miskito y kuna. La Paz.

Foucault, Michel (1992). Microfísica del poder. Madrid: La Piqueta.

Millaleo, Salvador (2014). « $i$ Gobernar consultado? El Convenio 169 en los reglamentos aprobados en Chile». En ¿Chile indígena? Desafíos y oportunidades para un nuevo trato. Santiago: Fundación Chile 21.

PÉrez, Carlos (1998). Sobre un concepto histórico de ciencia: De la epistemología actual a la dialéctica. Santiago: Lom.

Riveros, Claudio (2016). "Gabriel Salazar, La enervante levedad histórica de la clase politica civil (Chile, 1900-1973)». Izquierdas, 29: 275-279. DOI: 10.4067/ So718-50492016000400011.

SALAZAR, Gabriel (2015). La enervante levedad histórica de la clase política civil (Chile, 1900-1973). Santiago: Debate.

Sanhueza, Cristián, Daniel Saber, James Cavallaro, Jorge Contesse y César RoDRÍGUEZ (2013). No nos toman en cuenta: Pueblos indígenas y consulta previa en las pisciculturas de la Araucanía. Santiago: Universidad Diego Portales.

Torres Cisneros, Gustavo (2013). «Diplomacia indígena: Transitando del problema a la solución». Revista Mexicana de Política Exterior, 98: 197-232. Disponible en http://bit.ly/2QNodoX. 
Zalaquett Daher, José (2008). «La Declaración de Naciones Unidas sobre Derechos de los Pueblos Indígenas». Anuario de Derechos Humanos, 4: 139-148. DOI: 10.5354/0718-2279.2011.13508.

Zavala, Silvio (1994). Filosofía de la Conquista. 1. ${ }^{a}$ ed. de 1947. Santiago: Fondo de Cultura Económica.

ZEA, Leopoldo (1981). Latinoamérica en la encrucijada de su historia. Ciudad de México: UNAM.

\section{Sobre el autor}

Fernando Quilaleo Aguirre es periodista de la Universidad ARCIS, Chile. Magíster en Comunicación de la Universidad de Chile, candidato a doctor por la Universidad Nacional de Cuyo, Argentina. Su correo electrónico es kilaleo@gmail.com. 
El Anuario de Derechos Humanos es una publicación anual de referencia y consulta en derechos humanos y materias afines, que busca ser un espacio de discusión, difusión y conocimiento de los temas centrales sobre derechos humanos en sus contextos nacional e internacional, poniendo a la disposición del público de manera gratuita los distintos desarrollos doctrinales, jurisprudenciales y legislativos ocurridos en este campo dentro del período anual cubierto por cada edición.

\author{
DIRECTORA RESPONSABLE \\ Nancy Yáñez Fuenzalida \\ EDITOR DE CONTENIDOS \\ Salvador Millaleo \\ SITIO WEB \\ anuariocdh.uchile.cl \\ CORREO ELECTRÓNICO \\ anuario-cdh@derecho.uchile.cl
}

LICENCIA DE ESTE ARTÍ́CULO

Creative Commons Atribución Compartir Igual 4.0 Internacional

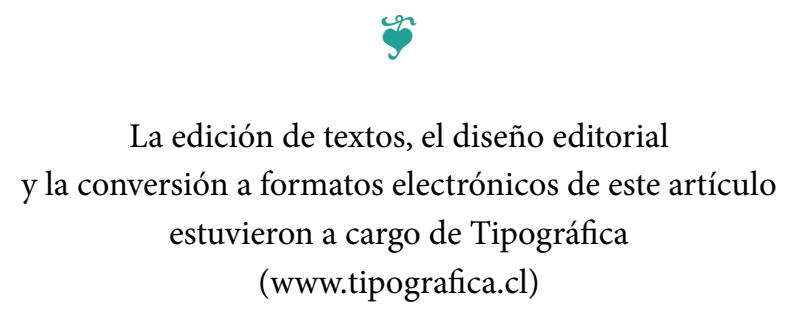

